\title{
Uma Proposta de Ensino para Alunos Surdos à Luz da Semiótica Social
}

\section{A Teaching Proposal for Deaf Students Based on Social Semiotics}

\section{Una Propuesta de Enseñanza para Estudiantes Sordos Basada en Semiotica Social}

\author{
(iD) \\ Tayana Dias de Menezes \\ Universidade Federal de Pernambuco
}

Resumo: O presente artigo tem dois objetivos principais, primeiro: refletir sobre o conceito da multimodalidade dentro da Semiótica Social e segundo: propor um exemplo de aula de português escrito, sustentado pelos pressupostos teóricos revisados no artigo, para alunos surdos usuários da libras. Para cumprir o primeiro objetivos, vamos discutir Kress e Leeuwen (2000; 2006); Dionísio (2014) e outros autores que se destacam dentro do tema abordado. Para cumprir o segundo objetivo, discutiremos, inicialmente, as particularidades dos sujeitos surdos e as metodologias de ensino mais adequadas para suprir as demandas educacionais deste sujeito. Alicerçados pela teoria e pela prática, em sala de aula, pretendemos elaborar uma proposta de ensino de português para surdos que seja flexível, ou seja, que possa servir como sustentáculo para variados temas e objetivos. Este artigo é, em parte, resultado dos trabalhos desenvolvidos pela atividade de extensão realizada pela UFPE sob o título: Ensino de língua portuguesa para surdos: estratégias didáticas.

Palavras-chave: Semiótica Social. Multimodalidade. Surdos. Estratégias Didáticas. 
Abstract: This article has two main objectives, first: to reflect on the concept of multimodality within Social Semiotics and second: to propose a example of written portuguese class, supported by the theoretical assumptions reviewed in the article, for deaf students who use libras - brazilian sign language. To fulfill the first objectives, we will discuss Kress and Leeuwen (2000; 2006); Dionísio (2014) and other authors who stand out within the topic addressed. To fulfill the second objective, we will discuss, initially, the particularities of the deaf individuals and the most appropriate teaching methodologies to supply the educational demands of this ones. Grounded on theory and practice, in the classroom, we intend to develop a proposal for teaching portuguese to the deaf that is flexible, in other words, that can serve as a support for various themes and objectives. This article is, partly, the result of the work developed by the extension activity carried out by UFPE under the title: Teaching the Portuguese language to the deaf: didactic strategies.

Keywords: Social Semiotics. Multimodality. Deaf. Didactic Strategies.

Resumen: Este artículo tiene dos objetivos principales, primero: reflexionar sobre el concepto de multimodalidad dentro de la semiótica social y segundo: proponer un ejemplo de una clase de portugués escrita, respaldada por los supuestos teóricos revisados en el artículo, para estudiantes sordos que usan libras. Para cumplir los primeros objetivos, discutiremos sobre Kress y Leeuwen (2000; 2006); Dionísio (2014) y otros autores que destacan dentro del tema abordado. Para cumplir con el segundo objetivo, discutiremos inicialmente las particularidades de los sordos y las metodologías de enseñanza más apropiadas para satisfacer sus demandas educativas. Con base en la teoría y la práctica, en el aula, tenemos la intención de desarrollar una propuesta para enseñar portugués a sordos que sea flexible, es decir, que pueda servir de 
apoyo para varios temas y objetivos. Este artículo es, en parte, el resultado del trabajo desarrollado por la actividad de extensión llevada a cabo por UFPE bajo el título: Enseñanza del idioma portugués para sordos: estrategias didácticas.

Palabras clave: semiótica social. Multimodalidad. Sordo. Estrategias didácticas.

Data de submissão: 08/07/2020

Data de aprovação: 06/11/2020

3

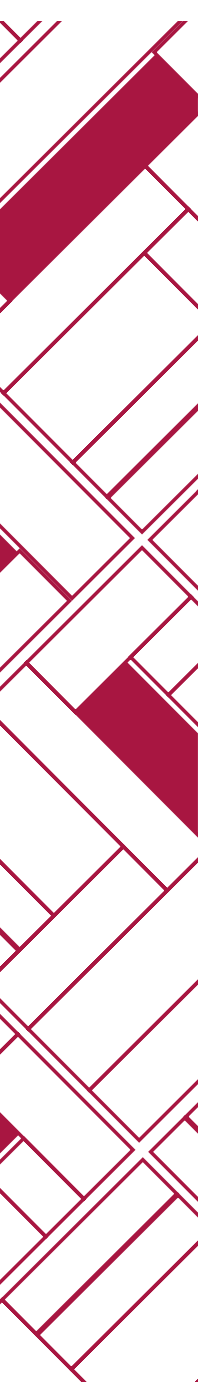


Uma Proposta de Ensino para Alunos Surdos à Luz da Semiótica Social

\section{Introdução}

Segundo Freire (1996), a teoria sem a prática é vazia, vira "verbalismo", no entanto a prática sem teoria vira ativismo. Mas, ao agregar a prática com a teoria, tem-se a práxis, a ação criadora e modificadora da realidade. O objetivo primeiro desse artigo é propor um exemplo de aula de língua portuguesa para surdos. Esses sujeitos, diferentemente dos ouvintes, captam a realidade especialmente por meio do olhos, por esse motivo a literatura especializada sugere o uso de imagens; vídeos como um canal facilitador da aprendizagem para esse novo público que encontramos dentro dos muros das escolas. No entanto, aqui cabe nos perguntar: o uso da imagem pela imagem irá garantir a aprendizagem? Assim como para ouvintes, na aula de português, o uso do texto como pretexto não garante que aconteça, de fato, a aprendizagem, trazer simplesmente imagens; vídeos; desenhos etc. para sala de aula também não irá garantir para surdo um aprendizado eficaz.

Para evitar cair na armadilha comentada por Freire - tornar a prática ativismo -, iremos propor um trabalho específico com o uso de imagens. Vale ressaltar que esta proposta é fruto de observações em sala de aula com alunos surdos e, em parte, resultado das reflexões da atividade de extensão - Ensino de língua portuguesa para surdos: estratégias didáticas ${ }^{1}$ - ainda em curso. Em outras palavras, a aula apresentada no presente artigo é uma sugestão que poderá ser, no futuro, aplicada para suprir as especificidades de ensino/ aprendizagem do sujeito surdo. O modelo de aula é flexível podendo, por isso, ser usado como sustentáculo para planejar outras tantas aulas sobre temas distintos da língua portuguesa. Mas, para isso, vamos antes refletir sobre a teoria que dá base para a prática, ou seja, vamos comentar aspectos funda-

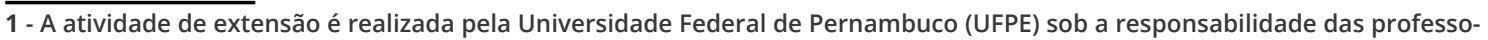
ras: Prof. Me. Camila Michelyne Muniz da Silva e da Prof. Dra Tayana Dias de Menezes - autora do presente artigo. 
Uma Proposta de Ensino para Alunos Surdos à Luz da Semiótica Social Tayana Dias de Menezes

mentais da Semiótica Social e como essa trata a multimodalidade - característica inerente a todos os textos. Mas, antes disso, é preciso comentar algumas particularidades sobre o surdo.

\title{
Especificidades Sobre os Surdos
}

Historicamente, a surdez é, recorrentemente, associada à deficiência. Por esse motivo, é fundamental pensar sobre os significados que dão forma ao conceito da deficiência.

\begin{abstract}
Por longos anos na história, termos como aleijado, inválido, incapacitado, defeituoso, desvalido ou excepcional, atribuíram àquele que tinha alguma deficiência o significado de "peso morto para a sociedade (Sassaki, 2003), além de considerálo como um fardo para a família. Nas palavras de Gugel, tais terminologias "continham em sua essência o preconceito de que se tratavam de pessoas sem valor, socialmente inúteis e dispensáveis do cotidiano social e produtivo" (Gugel, 2006, p. 25). Dentro desse debate, autores como Márcio d'Amaral (2004; 2008), Teresa d'Amaral (2004) e Lobo (2004) irão defender que a palavra "deficiente" traz um sentido negativo e excludente. (OLIVEIRA, 2010, p. 28- 29).
\end{abstract}

A citação é interessante posto que nos ajuda a refletir sobre os significados por trás dos nomes escolhidos para referir-se ao deficiente e, também, sobre a relação entre a palavra e a visão da época sobre o assunto. Os sujeitos surdos, segundo o conhecimento de senso comum, fazem parte da categoria deficiente e são, muitas vezes, encarados como "socialmente inúteis". Essa concepção, vem sendo questionada e acreditamos que uma das maneiras mais efetivas para alterar esse discurso é por meio da 
Uma Proposta de Ensino para Alunos Surdos à Luz da Semiótica Social Tayana Dias de Menezes

educação, isto é, tornar o surdo um sujeito agente dentro dos muros da escola.

O termo "surdo" é vago e demasiado geral, isto é, aplica-se a qualquer sujeito que tenha alguma perda auditiva. Existem graus de surdez variados: A surdez leve apresenta uma perda auditiva de até $40 \mathrm{~dB}$ - o que impede a percepção perfeita de todos os fonemas da palavra, mas não impede a aquisição natural da língua. Pode, no entanto, causar algum problema articulatório ou dificuldade na leitura e/ou escrita -, a surdez moderada apresenta perda auditiva entre 40 e $70 \mathrm{~dB}$ - aqui, quase nenhum som da fala pode ser percebido em nível de voz natural. Apenas sons fortes como choros de crianças e o de aspirador de pó funcionando são audíveis. Há ainda o grupo dos que abrange os indivíduos com surdez severa e os com surdez profunda. A surdez severa apresenta uma perda auditiva entre 70 e $90 \mathrm{~dB}$. O indivíduo com surdez profunda apresenta perda auditiva superior a $90 \mathrm{~dB}$. Na surdez severa, nenhum som de fala é audível e poucos sons podem ser percebidos (ex. toque de telefone no volume máximo). Já na surdez profunda nenhum som é entendido, alguns como serra elétrica, helicópteros podem ser captados.

Uma vez que os surdos têm pouco ou nenhum acesso ao som, na educação bilíngue o ensino/ aprendizagem deve ocorrer através da libras - e não do português oral, o canal tradicional de ensino/aprendizagem -, os seja, a língua usada em sala de aula deve ser a língua de sinais, considerada a primeira língua do grupo, mas estes devem também adquirir a língua oficial do seu país - no caso, o português escrito.

O conceito mais importante que a filosofia bilíngue traz é de que os surdos formam uma comunidade, com cultura e línguas próprias. A noção de que o surdo deve, a todo custo, tentar 
Uma Proposta de Ensino para Alunos Surdos à Luz da Semiótica Social

aprender a modalidade oral da língua para poder se aproximar o máximo possível do padrão de normalidade é rejeitada por essa filosofia. Isto não significa que a aprendizagem da língua oral não seja importante para o surdo, ao contrário, este aprendizado é bastante desejado, mas não é percebido como o único objetivo educacional do surdo nem como uma possibilidade de minimizar as diferenças causadas pela surdez (GOLDFELD, 2002, p. 43)

Nosso objetivo não é detalhar o bilinguismo - hoje, dentro da área da surdez, a filosofia educacional melhor aceita. A citação supracitada é interessante porque ela deixa claro que, diferente do que aconteceu no passado, o surdo; a escola e a comunidade devem aceitar a surdez. Isso significa afirma que o surdo não precisa almejar assemelhar-se ao grupo majoritário, mas deve assumir a sua surdez: sua cultura, seus traços identitários e sua língua. Esse posicionamento traz consequências para o padrão educacional tradicional. Teremos em sala de aula um sujeito falante de uma modalidade espaço-visual que interage por meio das mãos e do corpo e que capta a realidade a sua volta, especialmente, pelos olhos. Portanto, cabe ao professor, o papel de rever estratégias de ensino para atingir esse novo público: procurar engajar o estudante como agente construtor de seu próprio conhecimento; construir ambientes de aprendizagem adequados utilizando-se dos recursos apropriados para que os alunos reflitam criticamente.

Barbosa (2016, p.3) afirma que a surdez é encarada como uma "experiência visual", portanto, "o uso da informação verbal interligada à imagem, se configura como um facilitador para o ensino/aprendizagem desse público de alunos". Podemos dessa maneira concluir que o uso de recursos visuais pode ser uma meio facilitador para que ocorra de fato a aprendizagem. 
Uma Proposta de Ensino para Alunos Surdos à Luz da Semiótica Social Tayana Dias de Menezes

Embora defendamos que é, para a formação intelectual e cognitiva, fundamental que o surdo aprenda a libras como primeira língua, defendemos também que é importante para ele aprender a língua majoritária do seu país, especialmente, na modalidade escrita. É fundamental, por isso, que o professor tenha em mente que "aprender o português decorrerá do significado que essa língua assume nas práticas sociais [...] e esse valor só poderá ser conhecido por meio da língua de sinais. O letramento na língua portuguesa, portanto, é dependente da constituição de seu sentido na língua de sinais" (FERNANDES, 2006, p. 6).

Uma vez que o uso de imagens integrado ao texto verbal é um recurso possível e desejado dentro das estratégias de ensino para o aluno surdo, vamos, inicialmente, pensar na teoria que dá base para a análise das imagens para depois sugerir um trabalho que poderá ser eficaz para aulas de português.

\section{A Semiótica Social: Princípios Teóricos}

Dentre tantas outras teorias, por que a Semiótica Social (SS)? Para responder essa pergunta fundamental é preciso, pois, retomar o que foi discutido na sessão anterior. Inicialmente, é relevante lembrar que os surdos possuem como primeira língua a libras, sendo o português escrito uma segunda língua. A estrutura linguística da libras é distinta da do português, a língua de sinais brasileira é uma língua de modalidade espaço-visual, ou seja, os surdos captam a realidade por meio dos olhos e interagem com as mãos e o corpo. Podemos, por isso, concluir que imagens; vídeos; desenhos etc. gozam de um lugar privilegiado no processo de ensino/ aprendizagem dos surdos uma vez que estes utilizam os olhos para perceber/ entender/ refletir sobre a realidade. 
Uma Proposta de Ensino para Alunos Surdos à Luz da Semiótica Social Tayana Dias de Menezes

Retomando a pergunta inicial, a perspectiva sociossemiótica trata a linguagem verbal e as outras semioses equitativamente, isto é, não há uma hierarquia, dentro do texto, entre a linguagem verbal e os outros modos que (re)constroem os múltiplos significados. Isso significa afirmar que o professor pode, ao discutir sobre os significados do texto em sala de aula, partir das imagens e de outros modos para chegar à língua escrita.

Consciente do porquê da seleção da perspectiva teórica, vamos esquadrinhar melhor conceitos basilares desta: signo; modo; recursos semióticos; affordances e conjunto multimodal.

O conceito de signo remonta pensadores gregos, filósofos estoicos, perpassa as reflexões de Saussure e Pierce. Não iremos, por uma questão de espaço, fazer toda a trajetória teórica. Mas, o signo dentro da SS é encarado como "noção chave" (KRESS e VAN LEEUWEN, 2006, p. 6). Os autores de Reading image: the grammar of visual design propõem-se discutir sobre "formas (significantes) como cor, perspectiva e linha, bem como a maneira pela qual essas formas são usadas para realizar significados (significados) na construção dos signos" (KRESS e VAN LEEUWEN, 2006, 6) ${ }^{2}$ [as traduções foram feitas pela própria autora]. Podemos, por meio da citação, concluir que para a SS os signos são formas semióticas impregnadas de significados. Segundo os autores citados, o signo é uma combinação de forma e significado: a menor unidade de sentido.

Kress e Van Leeuwen (2006) defendem que o signo é motivado a partir do interesse dos agentes socais e do contexto de uso, "sob o nosso olhar o signo nunca é arbitrário, e a 'motivação' deve ser formulada na relação entre o criador do signo e o contexto que cada signo é produzido" (KRESS e VAN LEEUWEN, 2006,

\footnotetext{
2 - "the key notion in any semiotics is the sign. Our book is about signs - or, as we would rather put it, about sign-makers. We will be discussing forms (signifiers) such as colour, perspective and line, as well as the way in which these forms are used to realize meanings (signifieds) in the making signs".
} 
Uma Proposta de Ensino para Alunos Surdos à Luz da Semiótica Social Tayana Dias de Menezes

p. 8)3. Isto é, o signo é carregado de significado, mas esse é uma (re)construção motivada por interesse e produzida num contexto social específico. Dessa forma, o signo é um elemento atravessado por questões sociais, culturais e históricas. Por isso, a SS se debruça especialmente para o processo de produção de significado, os recursos ou modos usados na (re)construção do significado, os agentes sociais responsáveis pela (re)construção e o contexto em que esses significados atuam. Agentes sociais não selecionam signos aleatoriamente, antes:

\begin{abstract}
[...] são organizados em textos, como complexos de signos - um conjunto de elementos coerentes dentre de entidades textuais coerentes, estabelecendo um entrelaçamento, uma cadência entre vários signos utilizados numa interação social, um conjunto multimodal. Nessas configurações, percebemos a integração de diversos modos, na comunicação contemporânea, usando seus recursos materiais e conceituais na produção e orquestração de significados (SANTOS e GUALBERTO, 2019, p. 8).
\end{abstract}

A citação ratifica o motivo pelo qual a SS encara os signos como significações que ultrapassam os limites da língua e estão intrinsicamente relacionados com aspectos culturais, sociais e históricos. O signo existe em todos os modos, no entanto signo e modo são conceitos que não se confundem: o segundo diz respeito aos diferentes recursos usados para a (re)construção do significado dentro do texto, exemplo: imagens; gráficos; som; layout; mapas etc. Enquanto o primeiro, origina-se, como já mencionado, na tradição filosófica dos gregos; pensado também pelos estoicos - estes "já distinguiam entre expressão, conteúdo e referente", segundo Lacerda (1950, p. 20) - e perpassa os pensamentos de Saussure e

3 - "In our view signs are never arbitrary, and 'motivation' should be formulated inrelation to the sign-maker and the contexto in whitch the sign is produced". 
Uma Proposta de Ensino para Alunos Surdos à Luz da Semiótica Social Tayana Dias de Menezes

Pierce, diz respeito à menor unidade de sentido: uma combinação entre forma e significado. Os modos são definidos por Santos e Gualberto (2019, p. 10) "como os meios pelos quais o signo se torna evidente" e complementa que "é utilizado para se referir a um conjunto de recursos socialmente e culturalmente moldados para a produção de sentido" (p.10), os signos "se materializam por meio dos modos" (SANTOS e GUALBERTO, 2019, p. 12).

[...] os modos são resultados do trabalho semiótico de membros de uma comunidade específica e são continuamente desenvolvidos no seu uso, visto que as necessidades sociais e os interesses de uma comunidade tornam-se visíveis nos traços de cada modo. Nesta via, os significados são acordados socialmente e específicos cultural e socialmente. As escolhas de determinados modos para a produção de significados estão diretamente ligadas à história do uso semiótico de uma materialidade específica, dado que o que um produtor de signo faz está relacionado com o que outro(s) produtores fizeram antes, em resposta a necessidades sociais semióticas similares (SANTOS e GUALBERTO, 2019, p. 11).

Não apenas o signo é um elemento perpassado por questões históricas, sociais e culturais, os diversos modos também são. Cada modo tem suas possibilidades (affordances) de (re)construção, por exemplo na fala podemos usar o tom de voz, na escrita podemos usar diferentes fontes etc. Ou seja, affordances "indica as restrições e as possibilidades oferecidas por cada modo para a produção de sentido em eventos comunicativos" (SANTOS e GUALBERTO, 2019, p. 9).

Kress, segundo (SANTOS e GUALBERTO, 2019), defende que há principios semióticos comuns a todos indivíduos e estes 
Uma Proposta de Ensino para Alunos Surdos à Luz da Semiótica Social Tayana Dias de Menezes

"produzem signos em uma relação motivada. Esses signos, por sua vez, são produzidos por diferentes meios em diferentes modos e realizam os significados, usando os recursos semióticos disponíveis pelos membros de grupos sociais em uma determinada cultura" (p.5).

Podemos concluir que a multimodalidade é uma carcterística inerete aos textos, uma vez que estes apresentam muitos (multi) modos em sua (re)constituição. Desta forma, uma das preocupações da SS é refletir sobre a motivação do uso/ escolha de determinados modos na (re)construção de sentido, em contextos determinados, dentro de textos especificos como parte de uma construção social. A SS procura dar conta dos significados socais (re)construídos por meio das inúmeras forma semióticas e da relação da (re)construção do significado dentro das interações sociais situadas. Por isso, Santos e Gualberto (2019) apontam como princípios semióticos de trabalho: 1) a noção de escolha do sistema de linguagem; 2) as configurações de significado a partir do contexto; e 3) as funções semióticas da linguagem.

Podemos, portanto, concluir que a (re)construção do significado dentro do texto, para a SS, não parte apenas da linguagem estrita, mas se dá pelo conjunto de modos selecionados pelo agente no momento da interação num contexto específico para cumprir propósitos comunicativos. Dessa forma, nós, professores, podemos planejar uma aula de língua portuguesa e junto com nossos alunos esmiuçar os significados a partir dos modos que compõe os textos que serão analisados. Para os alunos surdos, podemos introduzir uma discursão a partir de imagen; desenhos; gráficos etc. para depois, junto aos conhecimentos já ativados por uma discussão anterior em libras, analisar e trabalhar a língua portuguesa escrita. 


\section{Análise e Proposta de Trabalho}

A nossa proposta de trabalho não corresponde apenas a uma aula, ela deve ser fracionada pelo menos em três aulas. Nossa sugestão, será trabalhar a argumentatividade por meio de recursos visuais e pelo uso do advérbio de intensidade, assim como Kress e Van Leeuwen (2006), acreditamos que "o que é expresso na linguagem através da escolha entre diferentes classes de palavras e estruturas de oração, pode, na comunicação visual, ser expresso através da escolha entre diferentes usos da cor ou diferentes estruturas composicionais (p. 2) ${ }^{4}$. Mas, para os surdos é interessante partirmos dos significados contruído pela imagem para depois partirmos para a linguagem verbal, esse processo - imagemlinguagem verbal - pode auxiliar esses alunos a compreender os efeitos de sentido (re)construídos pelos signos selecionados dentro do texto analisado.

Como dissemos anteriormente a aula pode servir de exemplo para outros tantos temas: basta o professor selecionar os gêneros adequados que dêm suporte para atingir os objetivos e os temas desejados.

Nossa proposta de aula é sustentada pelas observaçõe em sala compostas por alunos surdos; pelas reflexões motivadas pelas atividades em curso do projeto de extensão - Ensino de língua portuguesa para surdos: estratégias didáticas - e pela Semiótica Social. Defendemos, por isso, que os signos usados na construção dos textos são motivados por questões históricas, culturais, sociais e ideológicas:

[...] encaramos a representação como um processo no qual os criadores do signo [...] procuram fazer a representação de algum objeto, seja físico ou semiótico, e no qual o seu interesse

4 - "what is expressed in language throught the choice between different word classes and clause structures, may, in visual communication, be expressed through the choice between different uses of colour or different compositional structures". 
Uma Proposta de Ensino para Alunos Surdos à Luz da Semiótica Social

Tayana Dias de Menezes

pelo objeto, no momento da construção da representação, é um processo complexo, decorrentes da cultura, de aspectos sociais e psicológicos do criador do signo. O interesse é a fonte para se selecionar o que se vê como critério para a construção do objeto. Esse aspecto criterial é então considerado como adequadamente representativo do objeto (KRESS e VAN LEEUWEN, 2006, p. 7)5.

Portanto, podemos concluir que os textos são um conjunto de signos selecionados por um agente e estes, por sua vez, são organizados segundo os critérios que o produtor do texto julga importante para atingir determinado propósito comunicativo, além disso o olhar do agente sobre o objeto, seja físico ou semiótico, como aponta Kress e Van Leeuwen (2006), é organizado por meio desses critérios ou o "aspecto criterial".

Kress, Leite-Garcia, Van Leeuwen (2000) apontam a importância de ter consciência que tanto produtores como leitores têm poder sobre o texto. Ele é construído por meio do arranjo de signos complexos: "o interesse descreve a convergência de um complexo de fatores: histórias sociais e culturais, contextos sociais atuais, incluindo expectativas do produtor dos sinais sobre o ambiente comunicativo"6 (KRESS, LEITE-GARCIA, VAN LEEUWEN, 2000, p. 388). Isto é, os produtores selecionam os signos mais apropriados de cordo com os seus interesses comunicativos.

Desta maneira, o professor poderá dar início a sua aula, para orientar a leitura dos alunos, à semelhança de Dionísio (2014) que inicia as suas reflexões a partir do questionamento: "qual a função das imagens na construção do livro?" (p. 14). No nosso

\footnotetext{
5 - "[...] we see representation as a process in which the makers of signs [...] seek to make a representation of some object or entity, whether physical or semiotic, and in which their interest in the object, at the point of making the representation, is a complexo one, arising out of the cultural, social and psychological history of the sign-maker, and focused by the specific contexto in which the sign-maker produces the sign. That 'interest' is the source of the selection of what is seen as the criterial aspecto $f$ the object, and this criterial aspect is then regarded as adequately representative of the object in a given context. In other words, it is never the 'whole object' but only ever its criterial aspects which are represented.

6 - "el interés describe la convergencia de un complejo de factores: historias sociales y culturales, contextos sociales actuales, incluso estimaciones del productor de los signos acerca del entorno comunocativo".
} 
Uma Proposta de Ensino para Alunos Surdos à Luz da Semiótica Social Tayana Dias de Menezes

caso, o professor poderá interrogar: qual a função da imagem ou dos recursos semióticos - na construção dos significados que perpassam o texto? A resposta a essa pergunta ativará os conhecimentos que os alunos possuem sobre: o momento histórico; os sujeitos que estão envolvidos no evento comunicativo; a situação socio- econômica específica do momento etc. Dionísio (2014) explica o porquê da importancia da pergunta supracitada: "observar a cumplicidade entre gênero textual, linguagens e áreas do conhecimento é fundamental, visto que gráficos, tabelas, mapas, desenhos anatômicos, por exemplo, apresentam convenções que vão além das do sistema linguístico" (p. 14).

A aula e, consequentemente, a pergunta será referente à compreensão da charge:

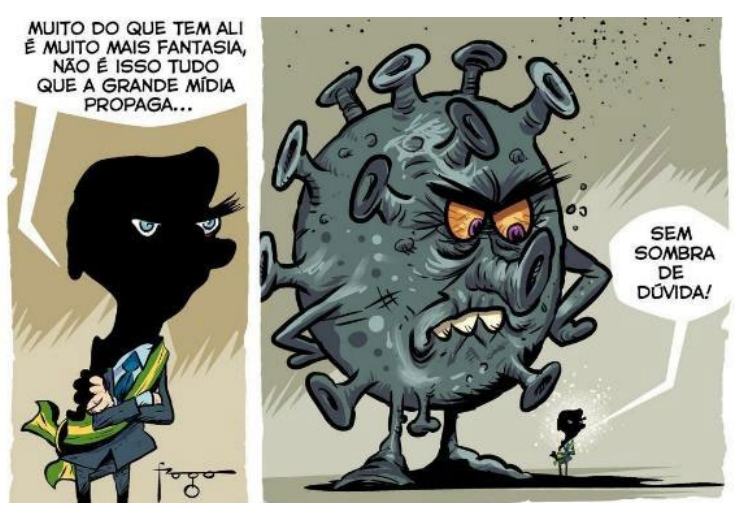

Imagem 1: Texto base para aula

https://gauchazh.clicrbs.com.br/opiniao/noticia/2020/03/gilmar-fraga-fantasia-ck7pbvcae03 z01pqgph2093v.html

A multimodalidade pressupões que os significados que atravessam o texto são construídos por meio de uma multiplicidade de modos. Assim, a aula de língua portuguesa deve se concentrar na análise e na reflexão dos recursos usados para gerar sentido dentro dos textos selecionados. Dionísio (2014), Kress e Van Leeuwen (1996) defendem que as imagens não são modos neutros, pelo 
Uma Proposta de Ensino para Alunos Surdos à Luz da Semiótica Social Tayana Dias de Menezes

contrário "o social e o cultural são influenciadores dos significados potenciais que a imagem pode encapsular". É, por isso, trabalho do professor junto com o aluno desencapsular os significados sociais e culturais que estão envolvidos nos modos que compõem o texto. A leitura, dessa maneira, será feita sob um olhar crítico e atento. "Os modos de representação verbal e visual não meramente coexistem" (DIONÍSIO, 2014, p. 61), antes eles se imbricam e (re)constroem um todo significativo. É preciso dessa maneira que o professor esteja atento: "a imbricação entre as somioses pode afetar a forma e a leitura da mensagem veiculada" ((DIONísıO, 2014, p. 63).

Segundo Kress, Leite-Garcia, Van Leeuwen (2000), uma análise de um texto multimodal sob a perspectiva da Semiótica social parte dos pressupostos: 1) "um conjunto de modos semióticos está sempre envolvido em qualquer produção ou leitura de textos"; 2) "cada modo tem suas potencialidades específicas de representação e comunicação, produzidas culturalmente, mas inerentes a cada modo" e 3) "é necessário entender a maneira de ler esses textos como textos coerentes em si mesmos"7 (p.388).

Desta maneira, os professores junto com os alunos poderão analisar os modos que compõe a charge e refletir sobre os possíveis efeitos de sentido levando em consideração o texto como um todo - um conjunto de signos - perpassado por questões sociais, culturais e ideológicas.

Inicialmente, o professor poderá chamar atenção para os personagens do texto e perguntar: quais são os signos que permitem os leitores idenfificarem os personagens? O primeiro personagem correspode a figura atual do presidente do Brasil e pode-se identificá-lo pelas semelhanças entre o sujeito e o desenho que o representa, além disso a faixa verde e amarelo - cores que reme-

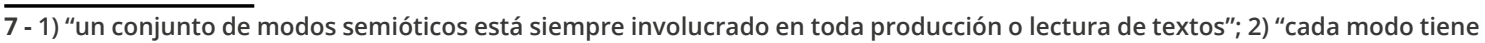
sus potencialidades específicas de representación y comunicación, producidas culturalmente pero inherentes a cada modo" e 3) "es preciso comprender la manera de leer esos textos como textos coherentes en sí mismos" 
Uma Proposta de Ensino para Alunos Surdos à Luz da Semiótica Social Tayana Dias de Menezes

tem ao Brasil - ratifica essa afirmação. O segundo personagem pode ser identificado como Coronavírus, dentro da mídia ele tem sido recorrentemente repersentado dessa maneira à semelhança de sua estrutura microscópica.

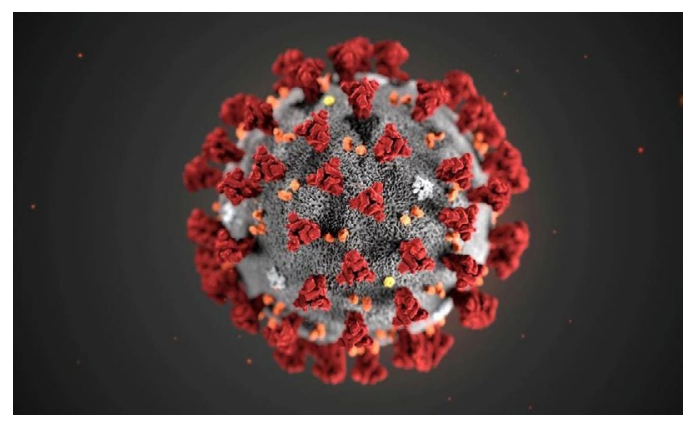

Imagem 2: Representação do Coronavírus

https://oglobo.globo.com/cultura/como-surgiu-imagem-que-virou-simbolo-do-coronavirus-24343397

Poder-se-á refletir junto com os alunos: se o vírus é um organismo microscópico, por que foi, no texto, representado num tamanho agigantado? Há algum objetivo nessa representação aparentemente desproporcional? Para dar sequencia à reflexão, o professor poderá relembrar o discurso do presidente no meio da crise quando classificou a pandemia como uma "gripezinha" e perguntar: qual foi a extensão da crise causada pelo coronavírus? Atingiu apenas o Brasil? Ou afetou outros países? Afetou apenas o sistema de saúde ou a crise se estendeu para outros segmentos socais? Essas perguntas, além de orientar a leitura do aluno, ajudará a turma ativar os conhecimentos necessários para compreender a charge.

Num primeiro momento, Bolsonaro aparece sombreado. Inicialmente não se sabe pelo o que ou por quem. A fala do personagem retratado retoma o tom recorrente de seus discursos: "Muito do que tem ali é muito mais fantasia, não é isso tudo que a grande mídia propaga...". O residente questiona a veracidade do que é informado pela mídia e afirma que tudo não passa de uma 
Uma Proposta de Ensino para Alunos Surdos à Luz da Semiótica Social Tayana Dias de Menezes

fantasia. Minimiza um problema mundial ao redizí-lo a mera fantasia criada pelos sistemas midiáticos.

Num segundo momento, vemos o que causa a sombra no presidente: o Coronavírus representado num tamanho desproporcional, agigantado. O professor poderá perguntar novamente aos alunos: por que o vírus foi representado dessa maneira? O problema que o mundo enfrenta é pequeno ou grande? Quantos mortos houve na Itália; França; Espanha; Brasil; EUA; Coreia; China etc? Um problama que afeta todo o mundo, é razoável classificá-lo como pequeno ou "fantasioso"? Houve um propósito comunicativo e argumentativo do produtor do signo ao retratar o vírus de uma maneira agigantada? Além de deixar claro o posicionamento do escritor sobre a pandemia que enfrentamos, o tamanho do vírus retoma o discurso do presidente e o põe em xeque: não se trata de uma gripezinha ou de uma fantasia criada pela grande mídia.

Podemos verificar que o agente causador do sombreamento na figura do presidente é o próprio vírus. A fala do próprio presidente chama atenção para a sombra causada pelo vírus "sem sombra de dúvidas!". A fala pode ser entendida como um trocadilho jocoso - uma vez que o gênero textual tem como objetivo fazer uma crítica política por meio do riso - , a expressão significa a certeza do que foi anteriormente dito, mas ela mesma desautoriza a fala do presidente: sua certeza não passa de uma asneira.

Depois de refletir sobre a charge com os alunos, o professor poderá perguntar a opinião individual de cada um sobre o assunto: isso é interessante para que se possa verificar quais são as informações que os alunos têm sobre o assunto.

O professor poderá também lembrar de que forma, na libras, se marca intensidade nos enunciados. Um exemplo das perguntas que poderão ser elaboradas pelo professor: se eu quisesse dizer que um rapaz é alto, como faria? Mas, se eu quisesse dizer 
Uma Proposta de Ensino para Alunos Surdos à Luz da Semiótica Social Tayana Dias de Menezes

que ele é MUITO alto, como faria? Poderá perguntar se há diferença entre ambas. Depois: se eu afirmasse que o problema causado pelo Coronavirus é grande, como o faria? E se eu quisesse dizer que ele é MUITO grande? Há também diferença de sentidos? Na Libras, a marcação de intensidade no enunciado se dá por meio da expressão facial ou na alteração do movimento do sinal ou ainda por uma intensificação na performance de um sinal na fala. Aqui, a comparação entre a Libras e o português poderá ajudar os surdos a entender de que maneira a intensidade dá peso ao argumento. O professor poderá, portanto, seguir uma linha de raciocínio e mostrar que o uso da intensidade, dentro do discurso, pode assumir peso argumentativo. Dessa forma, tanto o uso dos advébios de intensidade no discurso do presidente como a representação do vírus num tamanho agigantado possuem propósitos argumentativos.

Como a proposta de trabalho é português para surdos e um dos objetivos primeiros é trabalhar o português escrito, após o trabalho com a charge - já com os conhecimentos ativados sobre o assunto - o professor poderá introduzir um texto jornalístico ou de outro gênero que julgar adequado sobre o mesmo tema. Isso é importante porque os surdos precisam, para apreender o português e sua estrutura, sempre ter contato como o texto escrito. Nossa sugestão é que o texto, inicialmente, seja lido em português, depois algum aluno poderá traduzi-lo para libras. Seu conteúdo deverá ser discutido na língua de sinais. Depois de discutido em libras, o professor solicitará uma segunda leitura em português, uma mais atenciosa. E com base nos textos trabalhados, o professor poderá solicitar um texto sobre o vírus e suas consequências no cenário mundial. O texto deverá ser corrigido pelo professor, e os alunos precisarão, depois do texto corrigido pelo professor, reescrevê-lo. 
Uma Proposta de Ensino para Alunos Surdos à Luz da Semiótica Social Tayana Dias de Menezes

\section{Conclusões}

O presente artigo foi, em parte, fruto da atividade de extensão desenvolvida na UFPE intitulada, Ensino de língua portuguesa para surdos: estratégias didáticas. Discutimos, teoricamente embasados, as melhores estratégias didáticas para a aprendizagem efetiva da língua portuguesa escrita para alunos surdos. Na literatura especializada, defende-se recorrentemente o uso de imagens como um meio eficaz de se alcançar os objetivos de ensino. No entanto, o uso da imagem - ou de outros recursos - por si só não irá garantir um ensino/ aprendizagem significativo. Nosso objetivo, por esse motivo, foi refletir e embasar teoricamente, por meio dos pressupostos da Semiótica Social, o porquê do uso de recursos que exploram a visão é eficiente dentro de sala de aula especialmente para alunos surdos.

20

Levando em consideração que "[...] o sistema linguístico é apenas um dos modos de constituição dos textos que materializam as nossas ações sociais" (DIONísIO, 2014, p. 41), selecionamos uma charge para usá-la como sustetáculo para a nossa proposta, sendo essa uma sugestão de aula com o objetivo primeiro: analisar o uso de advérbios de intensidade e a "sintaxis visual" (KRESS, LEITE-GARCIA, VAN LEEUWEN, 2000, p. 376) na (re)contrução argumentativa do texto. Essa proposta é flexível, ou seja, pode-se usar a proposta de aula como base para outros tantos temas, além da possibilidade do uso de outro gênero textual.

Sabendo que os modos que constituem o texto são usados e selecionados com propósitos comunicativos específicos e são perpassados por questões históricas, culturais e sociais - "A ideologia, portanto, é um fator dos modos [...]" (KRESS, LEITE-GARCIA, VAN LEEUWEN, 2000, p. 375) -, cabe ao professor junto com os alunos desencapsular esses sentidos que atravessam o texto. 
Uma Proposta de Ensino para Alunos Surdos à Luz da Semiótica Social Tayana Dias de Menezes

A discussão inicial auxiliará os alunos ativarem os conhecimentos necessários para realizar uma leitura significativa. Daí, o professor pode trabalhar diversos temas e explorar outras tantas atividades de leitura/ escrita.

\section{Referências}

BARBosa, Eva dos reis. Português como segunda língua e multimodali-

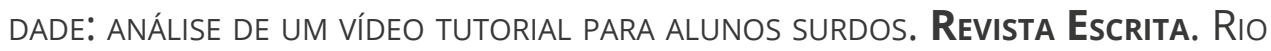
DE JANEIRO, N. 22, P. 1- 20, FEV. 2017.

DisPONÍVEL EM: HTTPS://WWW.MAXWELL.VRAC.PUC-IO.BR/COLECAO.PHP?STRSECAO=RESULTADO\&NRSEQ=28876@1. ACESSO EM: 20 JUn. 2019.

DiOnísio, Angela Paiva. Multimodalidades e leituras: funcionamento cognitivo, recursos semióticos, convenções visuais. ReCife: Pipa ComuniCAÇÕES, 2014.

ECKERT, A.; HIGGINS, D. [ILUSTRAÇÃo MÉdiCA do CoRonavírus]. DisPonível EM: HTTPS://OGLOBO.GLOBO.COM/CULTURA/COMO-SURGIU-IMAGEM-QUE-VIROU-SIMBOLO-DO-CORONAVIRUS-24343397. ACESSO EM: 12 JUN. 2020.

FERNANDES, Sueli F. Práticas de letramento na educação bilíngue para SURdos. In: SEED: CuRITIBA, 2006. Disponível EM:

HTTPS://CULTURA-SORDA.ORG/WP-CONTENT/UPLOADS/2015/O3/FERNANDES_PRATICAS_LETRAMENTOS-SURDOS_2006.PDF. ACESSO EM: 20 JUn. 2019.

fragA, Gilmar. Fantasia. Charge.

DISPONIVEL EM: HTTPS://GAUCHAZH.CLICRBS.COM.BR/OPINIAO/NOTICIA/2020/03/ GILMAR-FRAGA-FANTASIA-CK7PBVCAE03ZZ01 PQgPH2093V.HTML. ACESSO EM: 12 JUN. 2020.

Freire, PaUlo. Pedagogia da Autonomia. Rio de Janeiro: Paz e Terra, 1996. 
Uma Proposta de Ensino para Alunos Surdos à Luz da Semiótica Social Tayana Dias de Menezes

GOLDFELD, Marcia. A Criança SURda: linguagem e Cognição nUma PerSPeCtiva sociointeracionista. São Paulo: Plexus Editora, 2002.

GUAlBerto, Clarice L.; SANTOS. Zálra B. dos. Multimodalidade no contexto brasileiro: um estado de arte. D.E.L.T.A. São Paulo, vol.35, n.2, P. 1- 30, Aug 12, 2019. Disponívem em:

HTTP://200.144.145.24/DELTA/ARTICLE/VIEW/45274/29955. ACESSO EM: 15 JUL. 2020.

hONORA, MÁrcia; FRIZANCO, Mary L. Esteves. Livro Ilustrado de Língua Brasileira de Sinais. São Paulo: Ciranda Cultural, 2009.

LACERDA, ARaúJo InÊs. Do signo ao discurso: INTRODUÇÃo À FILOSOFIA DA linguagem. São Paulo: Parábola Editorial, 2004.

KRESS, G; VAN LEEUWEN, T. Reading Images: the GRAMAR of VISUAL DESIGN. LONDON: RoutLedGE, 1996.

KRESS, G.; LEITE-GARCIA, R.; VAN LEEUWEN, T. Semiótica Discursiva. In: VAN DIJK, T.A. El discurso como estructura y processo. Barcelona: Gedisa Editorial, 2000.

OliVeira, lilia Candella de. Visibilidade e Participação Política: Um estudo no Conselho Municipal da Pessoa com Deficiência em Niteról. Dissertação (Mestrado) - Pontifícia Universidade Católica do Rio de JanelRo, Departamento de Serviço Social, 2010. Disponível em: HTTP://WWW2.DBD.PUC-RIO.BR/PERGAMUM/TESESABERTAS/0812002_10_PRETEXTUAL.PDF. ACESSO EM: 20 JUN. 2019.

RUDLF, A. Arte e percepção visual: uma psicologia da visão criadora. São Paulo: Pioneira Thomson Learning, 2005.

SACKS, Oliver. Vendo vozes: uma viagem ao mundo dos surdos. São PauLO: Companhia dAS Letras, 2010. 